\title{
Assessing the Effects of ILeVO and VOTiVO Seed Treatments on Reproduction, Hatching, Motility, and Root Penetration of the Soybean Cyst Nematode, Heterodera glycines
}

\author{
Augustine Q. Beeman and Gregory L. Tylka, ${ }^{\dagger}$ Department of Plant Pathology and Microbiology, Iowa State University, Ames 50011
}

\begin{abstract}
Successful management of the soybean cyst nematode Heterodera glycines is limited by increased virulence of nematode populations on resistant soybean cultivars and persistence of the nematode in the soil in the absence of hosts. Seed treatments are now available for $\mathrm{H}$. glycines management. However, it is unclear how these treatments affect specific life stages of the nematode. The objectives of this study were to assess the effects of ILeVO (with active ingredient fluopyram) and VOTiVO (with active ingredient Bacillus firmus I-1582) seed treatments on $H$. glycines reproduction and important processes in the nematode life cycle, such as second-stage juvenile (J2) hatching, motility, and root penetration. The effects of seed treated with formulated (ILeVO and VOTiVO) and nonformulated active ingredient (fluopyram and B. firmus I-1582) on $H$. glycines reproduction were conducted in a greenhouse. Nematode reproduction on plants grown from seed treated with ILeVO or technical fluopyram (active ingredient only) was reduced by 35 to $97 \%$ relative to the nontreated control, suggesting that the fluopyram active ingredient

was affecting $H$. glycines directly and was not an inert ingredient in the seed treatment formulation. Hatching, motility, and root penetration experiments also were conducted using only the formulated seed treatments. Exudates collected from ILeVO-treated seed reduced J2 hatching and motility by more than $95 \%$ in laboratory assays. Exudates from radicles grown from ILeVO-treated seed reduced hatching in vitro by $48 \%$ in one run but had no significant effect in the second run compared with the nontreated control exudates. There also were no consistent effects of radicle exudates, regardless of treatment, on hatching and motility of the $\mathrm{J} 2$. ILeVO reduced root penetration of $H$. glycines $\mathrm{J} 2$ at different inoculation densities in a growth chamber experiment. VOTiVO did not affect any of the processes or life stages of the nematode studied. The results of this study indicate that the use of nematode-protectant seed treatments may be useful in controlling $H$. glycines; however, additional investigations into the precise effects of ILeVO and VOTiVO on $H$. glycines life processes and in different parts of the soil profile are necessary.
\end{abstract}

The soybean cyst nematode, Heterodera glycines Ichinohe, is the most damaging pathogen of soybean (Glycine max (L.) Merr.) in the United States (Allen et al. 2017). Growing nonhost crops such as maize (Zea mays L.), and soybean cultivars with resistance to the nematode can reduce $H$. glycines reproduction and soybean yield loss (Tylka et al. 2016). However, these management tactics have limitations. Eggs of the nematode can persist in the soil for many years, meaning that yield-suppressing densities of $H$. glycines may be present even after nonhost crops are grown several times in infested fields (Howard et al. 1998). Additionally, the incidence of virulent populations of $H$. glycines capable of reproducing on soybean cultivars containing the commonly used Plant Introduction (PI) 88788 source of resistance has increased in recent years (McCarville et al. 2017; Mitchum et al. 2007; Niblack et al. 2008). Long-term control of $H$. glycines requires incorporating additional management tactics along with nonhost crops and resistant soybean cultivars into an integrated management plan. An added management option is nematicides, which can reduce $H$. glycines population densities and increase soybean yields (Epps and Young 1981; Sasser and Uzzell 1991). The use of soil-applied nematicides often is not economical, and a number of the older products are no longer available due to environmental concerns (Ristaino and Thomas 1997; United States Environmental Protection Agency 1993). The limitations of soil-applied nematicides have led to increased interest in developing seed treatments for $H$. glycines management.

Nematode-protectant seed treatments contain active ingredients (AI) that protect against plant damage caused by plant-parasitic nematodes. The mode of action of these treatments varies; some affect nematodes directly whereas others protect plants indirectly via mechanisms such as inducing plant defense responses. The advantages of

${ }^{\dagger}$ Corresponding author: G. L. Tylka; E-mail: gltylka@iastate.edu

Accepted for publication 1 September 2017.

C) 2018 The American Phytopathological Society using seed treatments over soil-applied pesticides includes reduced amounts of AI used per hectare, the ability to add multiple different treatments to the same seed (i.e., fungicides, nematicides, and insecticides), and reduced effects of the pesticides on nontarget organisms (Munkvold et al. 2014). The first published report of using seed treatments to control plant-parasitic nematodes was in 1960 (O'Bannon and Reynolds 1960). The AI in the seed treatments examined since the initial report have been both chemical (Gray and Soh 1989; Rodriguez-Kabana et al. 1977) and biological (Oostendorp and Sikora 1989; Zuckerman et al. 1993). Only since 2006 has nematodeprotectant seed treatments become available for row crops like maize, cotton (Gossypium hirsutum L.), and soybean. There are currently several seed treatment options for $H$. glycines management, with more expected to come in the near future. Two current options are ILeVO (fluopyram; Bayer CropScience, Inc.) and VOTiVO (Bacillus firmus I-1582; Bayer CropScience, Inc.).

The performance of nematode-protectant seed treatments has been inconsistent in field studies, as measured by increased yields or decreased nematode reproduction (Barham et al. 2005; Tylka et al. 2015; Wheeler et al. 2013). The variable performance may be attributable to varying environmental conditions (Wheeler et al. 2013) that are largely unpredictable, making it difficult to forecast the potential economic return when using a seed treatment to manage plantparasitic nematodes (Gaspar et al. 2014). It also is unclear how initial nematode population densities in the soil affect the performance of nematode-protectant seed treatments.

The effects of these treatments on the biology of $H$. glycines are not well understood. That is, it is unclear what life stages and processes of the nematode life cycle are affected by various nematodeprotectant seed treatments and how long these treatments remain active. Determining how nematode-protectant seed treatments act on $H$. glycines will likely increase our ability to take advantage of this novel management tactic, potentially explain some of the field variability observed with these products, and direct future efforts to develop new seed treatments.

In addition to the specific effects of seed treatments on nematode biology, the movement of seed treatment AI through the seed and 
root zones of plants is not well understood, and likely varies depending on the specific product. There currently are no studies documenting the effects of seed treatments on root exudates. Faske and Starr (2007) found that abamectin seed treatment resulted in cotton root protection against Meloidogyne incognita but it was unclear whether this effect was due to the abamectin moving through the soil or on the root. It is possible that compounds or biological AI move on or through the root and are present at concentrations high enough for nematode protection. This hypothesis is particularly relevant for systemic compounds such as fluopyram.

The objectives of this study were to (i) assess the effects of ILeVO and VOTiVO seed treatments on reproduction of $H$. glycines under greenhouse conditions, (ii) determine the effect of seed and radicle exudates from treated seed on second-stage juvenile (J2) hatching and motility, and (iii) determine the effect of the seed treatments on $H$. glycines $\mathrm{J} 2$ root penetration at different inoculation densities and incubation times.

\section{Materials and Methods}

Seed treatments and source of $\boldsymbol{H}$. glycines inoculum. Soybean cultivars susceptible (cultivar Williams 82) and resistant (cultivar Jack, PI 88788) to $H$. glycines were treated by Bayer CropScience personnel. Treatments included B. firmus I-1582 and fluopyram as either the formulated product (VOTiVO or ILeVO) or the nonformulated AI alone. The nonformulated product contained only the AI with none of the carriers or polymers typically found in formulated seed treatments. Seed were treated with B. firmus I-1582 or fluopyram at the commercial rate of 5 million spores/seed or $0.15 \mathrm{mg} / \mathrm{seed}$, respectively. There were no colorants added to seed treated with formulated or nonformulated product. An HG Type $0 \mathrm{H}$. glycines population (Niblack et al. 2002) collected from an infested field (Fruitfield coarse sand soil, $\mathrm{pH} 7.6$, and 3.9\% organic matter) in Muscatine, IA, was used for the experiments and was maintained in the greenhouse on susceptible soybean (Williams 82).

Greenhouse experiments. Two separate experiments were conducted in the greenhouse with different initial population densities of $H$. glycines. One experiment used the field soil described above, with a population density of 4,000 eggs per $100 \mathrm{~cm}^{3}$ of soil. In the other experiment, the field soil was diluted 1:3 with construction sand to create an initial $\mathrm{H}$. glycines population density of 1,000 eggs per $100 \mathrm{~cm}^{3}$ of soil. The 4,000 eggs per $100 \mathrm{~cm}^{3}$ of soil will be referred to as moderate $H$. glycines population density soil and the 1,000 eggs per $100 \mathrm{~cm}^{3}$ of soil will be referred to as the low $H$. glycines population density soil, based on current extension guidelines (Tylka 2012).

Both the formulated (VOTiVO and ILeVO) and nonformulated ( $B$. firmus I-1582 and fluopyram) seed treatments were tested. Experiments were set up as a complete factorial and arranged in a randomized complete block design. Factors were soybean cultivar (Williams 82 and Jack) and seed treatment (VOTiVO, B. firmus I-1582, ILeVO, fluopyram, and nontreated control). Seed were planted in plastic cone-tainers (Stuewe and Sons, Inc.) containing $150 \mathrm{~cm}^{3}$ of soil. To regulate temperature, cone-tainers were placed in buckets filled with construction sand and incubated in a greenhouse water bath set to $27^{\circ} \mathrm{C}$. Each bucket served as a block and contained all cultivarseed treatment combinations. Plants were watered every 2 to 3 days. Thirty days after planting, $H$. glycines females were dislodged from roots using a stream of water and were collected on a $250-\mu \mathrm{m}$-pore sieve. Roots were dried in an oven at $70^{\circ} \mathrm{C}$ for at least $24 \mathrm{~h}$ and their weights recorded. Females were counted on a AZ100 Multizoom microscope (Nikon Corp.) at $\times 10$ magnification before they were crushed with a motorized rubber stopper (Faghihi and Ferris 2000) to release the eggs, which were collected on a $25-\mu \mathrm{m}$-pore sieve. The eggs were stained with acid fuchsin (Niblack et al. 1993 ) and counted under the same microscope at $\times 20$ magnification. Each of the two different experiments contained seven replications of each cultivar-seed treatment combination, and each experiment was conducted twice.

Collection of seed and radicle exudates. Seed and radicle exudates were collected from treated (VOTiVO and ILeVO) and nontreated susceptible soybean seed (Williams 82) for J2 hatching and motility experiments. A method adapted from other studies using seed and radicle exudates was used (Riga et al. 2005; Zhao et al. 2000). The previously published methods collected seed or radicle exudates in sterile water at room temperature. In our studies, exudates were collected by placing seed in a 50-ml beaker with a ratio of one seed per $5 \mathrm{ml}$ of sterile, distilled water. Radicle exudates were collected similarly by germinating seed on $1.5 \%$ water agar for 3 days at $25^{\circ} \mathrm{C}$, then placing the radicles ( 5 to $7 \mathrm{~cm}$ in length) of intact seedlings in a $50-\mathrm{ml}$ beaker with a ratio of one radicle per $5 \mathrm{ml}$ of sterile water. The seed and seed coat were suspended on cheesecloth and did not touch the water during radicle exudate collection. The beakers were agitated on a platform shaker for $1 \mathrm{~h}$ at $100 \mathrm{rpm}$ at room temperature (approximately $23^{\circ} \mathrm{C}$ ), and exudates were filtered through $30-\mu \mathrm{m}-$ pore nylon mesh after collection to remove debris. To compare the effects of exudate sterility on $H$. glycines in the $\mathrm{J} 2$ hatching and juvenile motility experiments, half of the exudates were filter sterilized by passing the solutions through a $0.22-\mu \mathrm{m}$-pore filter. The filtering was done primarily to determine if the presence or absence of $B$. firmus I-1582 cells in the VOTiVO exudates affected hatching. All exudates were stored at $4^{\circ} \mathrm{C}$ and used within a week of collection.

Hatching experiments. $H$. glycines females and cysts (dead females) were collected from 4- to 8-week-old $H$. glycines-infected soybean (Williams 82) by dislodging the nematodes from roots using a stream of water and collecting them on a $250-\mu \mathrm{m}$-pore sieve. The females and cysts were crushed with a motorized rubber stopper as described previously, and eggs inside of the females and cysts were collected on a $25-\mu \mathrm{m}$-pore sieve. Eggs were further separated from soil debris using sucrose centrifugation (Jenkins 1964) and rinsed three times with sterile, distilled water before use in hatch studies.

The effects of seed and radicle exudates were studied in separate experiments. Sterile, distilled water and $5 \mathrm{mM}$ zinc sulfate served as negative and positive controls, respectively (Tefft and Bone 1984), in both experiments. The experiments were set up in a factorial design and included the factors sterility and exudate. Each experimental unit consisted of an average of $232 \pm 53$ (mean \pm standard deviation) $H$. glycines eggs on a $30-\mu \mathrm{m}$-pore microsieve constructed from nylon mesh (Elko Filtering Co.) and plastic test tube caps (Wong et al. 1993). The sieves containing the eggs were incubated in $3 \mathrm{ml}$ of exudates in 3-cm-diameter Petri dishes. The hatching experiments were set up inside of an incubator at $25^{\circ} \mathrm{C}$. $\mathrm{J} 2$ that hatched and migrated down through the sieves into the liquid in the bottom of the dishes were counted at 3,7 , and 14 days under a microscope at $\times 20$ magnification, and microsieves were transferred to Petri dishes with fresh solutions at 3 and 7 days. Eggs and $\mathbf{J} 2$ remaining on microsieves were counted at day 14. Cumulative percent hatch was determined by dividing the number of hatched juveniles by the number of hatched juveniles plus the remaining unhatched eggs and then multiplying by 100 . There were four replications of each seed treatmentsterility combination and the two controls (sterile water and $5 \mathrm{mM}$ $\mathrm{ZnSO}_{4}$ ), and the experiments were each conducted twice.

Motility experiments. The effects of seed and radicle exudates on $H$. glycines $\mathrm{J} 2$ motility were tested in separate experiments. The experiments were set up in a factorial design. Sterile, distilled water served as a negative control. Factors were sterility (water control was sterile only) and seed or radicle exudates. An average of $36 \pm$ 16 (mean \pm standard deviation) $H$. glycines $\mathrm{J} 2$ that were hatched in sterile, distilled water within $48 \mathrm{~h}$ were incubated in $500 \mu \mathrm{l}$ of treatment solution in a $1-\mathrm{cm}$-diameter watch glass. The experiments were set up in an incubator at $25^{\circ} \mathrm{C}$. The $\mathrm{J} 2$ were visually rated as motile or nonmotile after 2 and $24 \mathrm{~h}$ of incubation in treatment solutions using a microscope at $\times 20$ magnification. A $\mathrm{J} 2$ was considered nonmotile if it did not move after being touched with a thin wire probe (Faske and Starr 2007; Schroeder and MacGuidwin 2010). There were four replications of each seed treatment-sterility combination and the sterile water control, and the experiments were conducted twice.

Root penetration experiment. The experiment was conducted in a growth chamber $\left(16 \mathrm{~h}\right.$ of light and $8 \mathrm{~h}$ of darkness, $\left.25^{\circ} \mathrm{C}\right)$ using H. glycines-susceptible soybean (Williams 82) grown from seed that were nontreated or treated with formulated seed treatments (VOTiVO 
and ILeVO). A complete factorial treatment arrangement and a randomized complete block design were used in this experiment. Factors included seed treatment, inoculation density, and incubation time. Seed were planted in a pasteurized, 2:1 sand/soil mixture in conetainers placed in buckets filled with construction sand. A sand-filled bucket containing a cone with each of the 12 treatment-inoculation density-incubation time combinations served as a block. Five days after planting, seedlings were inoculated with either 100 or $500 \mathrm{~J} 2$ (hatched in water within 3 days) by placing $500 \mu \mathrm{l}$ of $\mathrm{J} 2$ in a water suspension into $3-\mathrm{cm}$-deep holes located $1 \mathrm{~cm}$ from the base of the seedling. Soybean inoculated with $H$. glycines $\mathrm{J} 2$ were incubated for 1 or 3 days before being carefully washed and stained with acid fuchsin (Byrd et al. 1983). Roots were examined under the microscope $(\times 20$ magnification), and $\mathrm{J} 2$ that had penetrated roots were counted. There were five replications of each seed treatment-inoculation densityincubation time combination, and the experiment was conducted twice.

Statistical analyses. Statistical analyses were conducted in SAS (version 9.4; SAS Institute, Inc.) using PROC GLIMMIX. For the statistical models, the following factors were considered fixed effects: seed treatment (all experiments), cultivar (greenhouse experiment), sterility (hatching and motility experiments), inoculation density (root penetration experiments), and block (greenhouse and root penetration experiments). The factor block was nested in run, and the factor run was considered a random factor. An analysis of variance using the normal distribution was conducted for each experiment, and main and interactive effects were analyzed for significance. The control solutions (water and $\mathrm{ZnSO}_{4}$ for the hatching experiments and water for the motility experiments) were not included with the exudate solutions in the initial two-factor analyses for the hatching and motility experiments because the control solutions were sterile only (and, thus, the sterility factor could not be tested with the control solutions). If the sterility factor was not significant, the data from the sterile and nonsterile exudates were combined for analysis, with the additional sterile control solutions as a single factor experiment with unbalanced numbers of replications. For the experiments with unbalanced number of replications across treatments (hatching and motility studies), a Kenward-Roger adjustment was used to adjust the degrees of freedom. Data from staining times of 1 and 3 days after inoculation (DAI) were analyzed separately in the root penetration experiment. For all experiments, the separation of treatment means was done using Tukey's honestly significant difference test $(\alpha=0.05)$.

\section{Results}

Greenhouse experiments. The experiment with moderate $H$. glycines population density soil (4,000 eggs per $100 \mathrm{~cm}^{3}$ of soil) and the experiment with the low $H$. glycines density soil (1,000 eggs per $100 \mathrm{~cm}^{3}$ of soil) each were conducted twice and the data were analyzed separately. There was a significant interactive effect of seed treatment and cultivar for the majority of the response variables measured (females per root, eggs per root, root weight, eggs per gram of root, and females per gram of root); therefore, data from each cultivar were analyzed separately. Across all experiments, the number of females per root on the resistant cultivar (Jack) were $10 \%$ or less of the susceptible variety (Williams 82) (Tables 1 and 2).

For the moderate $H$. glycines population density soil experiment, the seed treatment factor significantly affected three of the five measured variables in the susceptible cultivar (Table 1). In contrast, no variables were significantly affected by seed treatment in resistant Jack. The roots of susceptible soybean grown from seed treated with ILeVO had $35 \%$ fewer females relative to the nontreated control (Table 1). There was no significant difference between the nonformulated fluopyram and the nontreated control in terms of the number of females. However, both ILeVO and fluopyram reduced the number of eggs per root compared with the nontreated control. Also,

Table 1. Reproduction of Heterodera glycines on soybean after 30 days using field soil $\left(4,000 \text { eggs per } 100 \mathrm{~cm}^{3} \text { of soil }\right)^{\mathrm{z}}$

\begin{tabular}{|c|c|c|c|c|c|}
\hline Cultivar, treatment & Females per root & Eggs per root & Root weight (g) & Females per gram of root & Eggs per gram of root \\
\hline \multicolumn{6}{|c|}{ Williams 82 (susceptible) } \\
\hline VOTiVO & $476 \mathrm{a}$ & $106,973 \mathrm{a}$ & $0.46 \mathrm{a}$ & $1,122 \mathrm{a}$ & $261,388 \mathrm{a}$ \\
\hline Bacillus firmus & $376 \mathrm{abc}$ & $84,100 \mathrm{ab}$ & $0.41 \mathrm{ab}$ & $1,063 \mathrm{a}$ & $249,367 \mathrm{a}$ \\
\hline ILeVO & $263 \mathrm{c}$ & $51,214 \mathrm{c}$ & $0.31 \mathrm{bc}$ & $1,043 \mathrm{a}$ & $205,943 \mathrm{a}$ \\
\hline Fluopyram & $286 \mathrm{bc}$ & $62,659 \mathrm{bc}$ & $0.32 \mathrm{c}$ & $1,127 \mathrm{a}$ & $260,099 \mathrm{a}$ \\
\hline Nontreated & $404 \mathrm{ab}$ & $93,432 \mathrm{a}$ & $0.46 \mathrm{a}$ & $1,020 \mathrm{a}$ & $245,142 \mathrm{a}$ \\
\hline \multicolumn{6}{|l|}{ Jack (resistant) } \\
\hline VOTiVO & $47 \mathrm{a}$ & $6,558 \mathrm{a}$ & $0.38 \mathrm{a}$ & $143 \mathrm{a}$ & $22,529 \mathrm{a}$ \\
\hline B. firmus & $40 \mathrm{a}$ & $7,573 \mathrm{a}$ & $0.36 \mathrm{a}$ & $130 \mathrm{a}$ & $22,272 \mathrm{a}$ \\
\hline ILeVO & $36 \mathrm{a}$ & $4,901 \mathrm{a}$ & $0.33 \mathrm{a}$ & $112 \mathrm{a}$ & $15,108 \mathrm{a}$ \\
\hline Fluopyram & $34 \mathrm{a}$ & $6,100 \mathrm{a}$ & $0.37 \mathrm{a}$ & $90 \mathrm{a}$ & $16,062 \mathrm{a}$ \\
\hline Nontreated & $38 \mathrm{a}$ & $5,593 \mathrm{a}$ & $0.38 \mathrm{a}$ & $102 \mathrm{a}$ & $14,838 \mathrm{a}$ \\
\hline
\end{tabular}

${ }^{\mathrm{z}}$ Values are least-squared means of 14 replications over two experimental runs. The two soybean cultivars tested were analyzed separately. Different letters in the same column for each cultivar represent significant differences according to Tukey's honestly significant difference test $(\alpha=0.05)$.

Table 2. Reproduction of Heterodera glycines on soybean after 30 days using a diluted field soil $\left(1,000 \text { eggs per } 100 \mathrm{~cm}^{3} \text { of soil }\right)^{\mathrm{z}}$

\begin{tabular}{|c|c|c|c|c|c|}
\hline Cultivar, treatment & Females per root & Eggs per root & Root weight (g) & Females per gram of root & Eggs per gram of root \\
\hline \multicolumn{6}{|c|}{ Williams 82 (susceptible) } \\
\hline VOTiVO & $200 \mathrm{a}$ & $53,664 \mathrm{a}$ & $0.24 \mathrm{ab}$ & $821 \mathrm{a}$ & $218,543 \mathrm{a}$ \\
\hline Bacillus firmus & $209 a$ & $58,300 \mathrm{a}$ & $0.28 \mathrm{a}$ & $767 \mathrm{a}$ & $212,784 \mathrm{a}$ \\
\hline ILeVO & $7 \mathrm{~b}$ & $1,414 \mathrm{~b}$ & $0.22 \mathrm{~b}$ & $32 \mathrm{~b}$ & $6,759 \mathrm{~b}$ \\
\hline Fluopyram & $18 \mathrm{~b}$ & $4,579 \mathrm{~b}$ & $0.23 \mathrm{ab}$ & $94 \mathrm{~b}$ & $24,006 \mathrm{~b}$ \\
\hline Nontreated & $199 \mathrm{a}$ & $49,250 \mathrm{a}$ & $0.29 \mathrm{a}$ & $753 \mathrm{a}$ & 183,385 a \\
\hline \multicolumn{6}{|l|}{ Jack (resistant) } \\
\hline VOTiVO & $9 \mathrm{ab}$ & $1,543 \mathrm{a}$ & $0.26 \mathrm{ab}$ & $35 \mathrm{a}$ & $6,172 \mathrm{a}$ \\
\hline B. firmus & $12 \mathrm{a}$ & $1,907 \mathrm{a}$ & $0.27 \mathrm{a}$ & $42 \mathrm{a}$ & 6,856 a \\
\hline ILeVO & $2 \mathrm{c}$ & $579 \mathrm{~b}$ & $0.21 \mathrm{~b}$ & $7 \mathrm{~b}$ & $2,636 \mathrm{~b}$ \\
\hline Fluopyram & $3 \mathrm{bc}$ & $593 \mathrm{~b}$ & $0.23 \mathrm{ab}$ & $15 \mathrm{ab}$ & $2,668 \mathrm{~b}$ \\
\hline Nontreated & $8 a b c$ & $1,171 \mathrm{a}$ & $0.25 \mathrm{~b}$ & $35 \mathrm{a}$ & $4,841 \mathrm{ab}$ \\
\hline
\end{tabular}

${ }^{\mathrm{z}}$ Values are least-squared means of 14 replications over two experimental runs. The two soybean cultivars tested were analyzed separately. Different letters in the same column for each cultivar represent significant differences according to Tukey's honestly significant difference test $(\alpha=0.05)$. 
formulated ILeVO and nonformulated fluopyram significantly lowered root weights compared with the nontreated control in the susceptible cultivar but not the resistant cultivar. There was no significant difference between the nontreated control and VOTiVO (formulated B. firmus $\mathrm{I}-1582$ ) or nonformulated B. firmus $\mathrm{I}-1582$ seed treatments for nematode reproduction or root weights in either cultivar (Table 1).

In the experiment where the low $H$. glycines population density was used, there were significant differences due to the ILeVO seed treatment in both susceptible and resistant cultivars (Table 2). The roots of susceptible soybean grown from seed treated with ILeVO (formulated fluopyram) and nonformulated fluopyram had 96 and $91 \%$ fewer females, respectively, compared with the nontreated control, and there was a similar trend for eggs per root. ILeVO also reduced females per root in resistant soybean by $75 \%$ compared with the nontreated control but the number of females per root on plants grown from seed treated with technical fluopyram was not significantly different from the nontreated control. Both ILeVO and fluopyram significantly reduced the number of eggs per root by about $50 \%$. There were reduced root weights for both cultivars tested with ILeVO and nonformulated fluopyram. Even with reduced root weights, fluopyram seed treatments significantly reduced the number of females and eggs per gram of root by more than $90 \%$ in the susceptible cultivar. However, ILeVO reduced only the number of females per gram of root in the resistant cultivar, and there were no significant effects of fluopyram on females or eggs per gram of root in the resistant cultivar. There was no effect of VOTiVO or $B$. firmus I-1582 seed treatments relative to the nontreated control on any of the variables measured for either cultivar (Table 2).

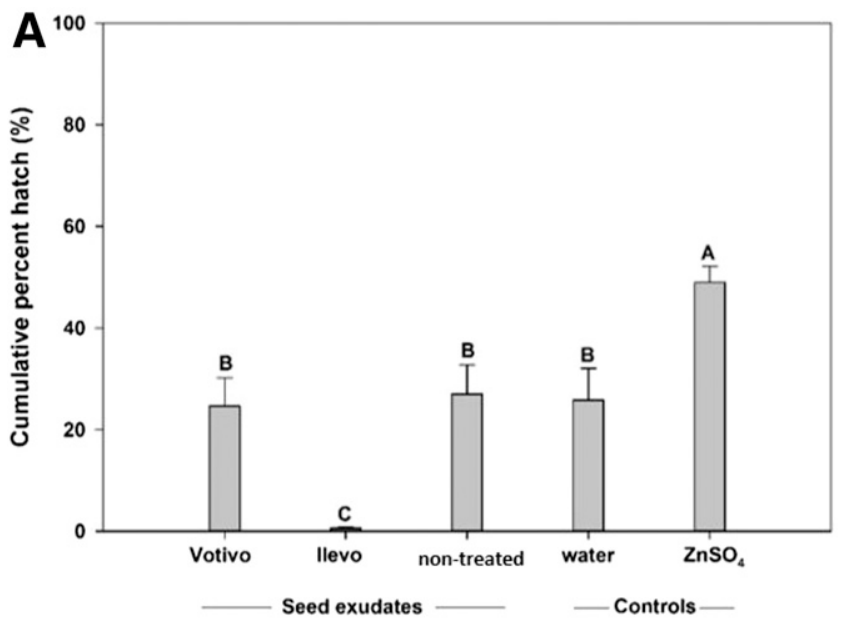

B

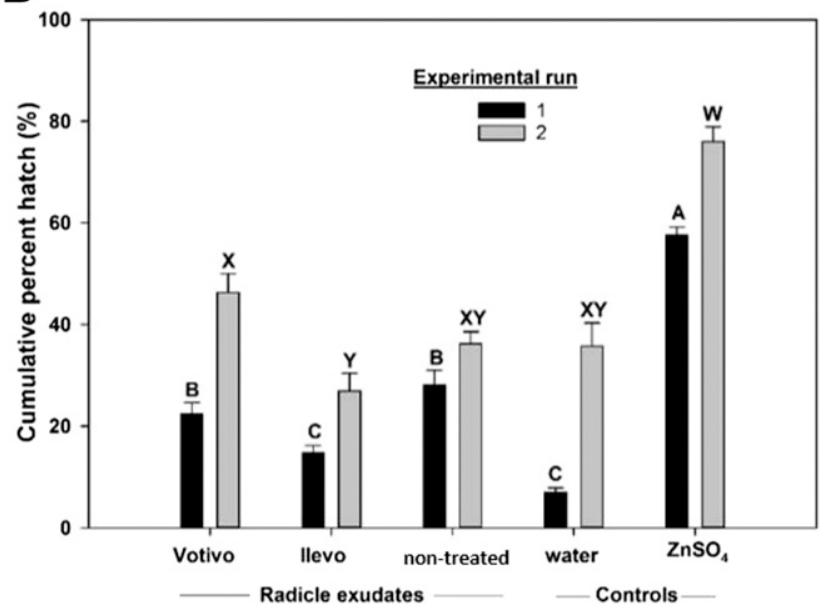

Fig. 1. Effect of $\mathbf{A}$, seed and $\mathbf{B}$, radicle exudates on cumulative percent hatching of Heterodera glycines juveniles (mean \pm standard error of the mean) over 14 days. There were 16 replications for seed exudates over two runs and 8 replications per run for the radicle exudates.
Hatching experiments. There was no significant difference in hatching between sterile and nonsterile seed or radicle exudates (data not shown); therefore, data from sterile and nonsterile exudates were combined, and the control solutions then were analyzed with the exudates. Both seed and radicle exudates had a significant effect on $H$. glycines hatching. There was no effect of exudates collected from VOTiVO-treated seed on hatching but exudates from ILeVO-treated seed significantly reduced hatching by $98 \%$ compared with hatching in exudates from nontreated seed (Fig. 1A). Regardless of treatment, seed exudates did not significantly stimulate hatching compared with the water control (Fig. 1A).

There was a significant interaction between the effects of seed treatment and experimental run with radicle exudates; therefore, data from the two runs were analyzed separately. Overall, hatching of H. glycines in radicle exudates and controls was higher in the first run compared with the second run. Radicles grown from VOTiVOtreated seed did not significantly affect hatching relative to the nontreated control in either run. In the first run, ILeVO radicle exudates reduced nematode hatching by $48 \%$ compared with the nontreated control but this did not occur in the second run. Also, exudates from radicles across all treatments significantly stimulated hatching relative to the water control in the first run but not in the second (Fig. 1B).

Motility experiments. There was no significant difference in motility of $\mathrm{J} 2$ between sterile and nonsterile seed or radicle exudates (data not shown); therefore, the data were combined and the water control was added for analysis for both sets of experiments. Seed and radicle exudates did not stimulate $\mathrm{J} 2$ motility relative to the water control (Fig. 2). Exudates from seed treated with ILeVO significantly
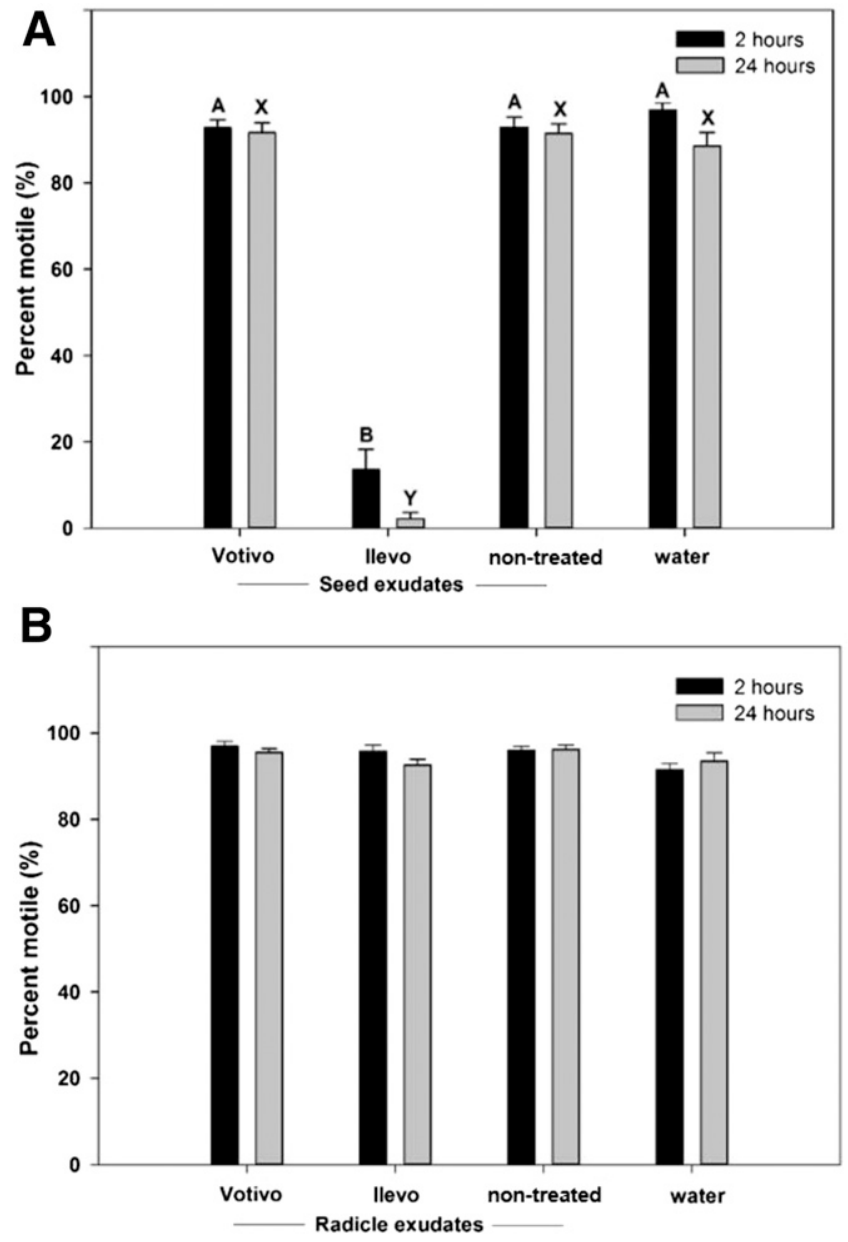

Fig. 2. Effect of $\mathbf{A}$, seed and $\mathbf{B}$, radicle exudates on motility of Heterodera glycines juveniles (mean \pm standard error of the mean) after 2 and $24 \mathrm{~h}$ of exposure. There were 16 replications for the exudates and eight replications for the water-only control solution over two runs. Bars of the same color with different letters are significantly different from one another according to Tukey's honest-significant-difference test $(\alpha=0.05)$. 
reduced $\mathrm{J} 2$ motility by 85 and $98 \%$ after 2 and $24 \mathrm{~h}$ of incubation, respectively, compared with the nontreated control (Fig. 2A). In contrast, exudates collected from seed treated with VOTiVO did not affect $\mathrm{J} 2$ motility (Fig. 2A). Motility of $H$. glycines $\mathrm{J} 2$ incubated in ILeVO or VOTiVO or nontreated radicle exudates was no different from each other or the water control (Fig. 2B).

Root penetration experiment. Half of the soybean roots were stained and the $\mathrm{J} 2$ were counted $1 \mathrm{DAI}$, and the remaining roots were stained and J2s counted 3 DAI. Data from the two time points were analyzed separately. There also was a significant interactive effect between seed treatment and $H$. glycines inoculation density for both time points; therefore, the two inoculation density treatments were analyzed separately (data not shown). At 1 DAI, there was no significant difference in root penetration detected between ILeVO and VOTiVO and the nontreated control at the lower inoculation density (100 J2/plant) but there was a significant, $79 \%$ decrease in the number of $\mathrm{J} 2$ infecting roots in the ILeVO treatment compared with the nontreated control for the higher inoculation density (500 J2/ plant) (Fig. 3A). At 3 DAI, there were 61 and $79 \%$ fewer penetrated $\mathrm{J} 2$ in the ILeVO treatment at the lower and higher inoculation density, respectively, compared with the nontreated control (Fig. 3B). There was no significant effect of VOTiVO on $H$. glycines $\mathrm{J} 2$ root penetration compared with the nontreated control or ILeVO at any inoculation density or time point (Fig. 3).

\section{Discussion}

ILeVO significantly reduced $H$. glycines reproduction, hatching, motility, and root penetration. In the greenhouse experiments, nonformulated seed treatments containing only the AI without the inert ingredients found in formulated seed treatments were tested along with formulated products. It was necessary to conduct experiments with AI-only treatments as well as the formulated products because it had not been shown in published reports that the fungicide AI of ILeVO, named fluopyram, was responsible for nematode suppression. It also is important to note that, although soybean seeds are typically treated with multiple products (fungicides, insecticides, and nematicides), the seed used in our experiments were only treated with the nematode products; namely, ILeVO and VOTiVO. ILeVO (formulated fluopyram) and nonformulated fluopyram had similar effects in both sets of greenhouse experiments. Both ILeVO and nonformulated fluopyram reduced the number of females and eggs per root in our experiments, particularly on the susceptible cultivar. Our results also suggest that initial nematode population density may be an important factor to consider when evaluating seed treatments. It is unclear why ILeVO reduced $H$. glycines more at a lower initial nematode population density compared with a moderate nematode population density. One possibility is that the amount of fluopyram applied to the seed was not enough to act on a critical number of nematodes at moderate $H$. glycines population densities. Also, it is possible that the increased sand content of the soil (used to dilute the field soil in our experiments) allowed for greater movement of the fluopyram or improved the efficacy of fluopyram in some other way. Because we tested different population densities in separate experiments, it is not possible to make conclusive statements on interactions between ILeVO and $H$. glycines population density. Additional seed treatment research where soybean is inoculated with different amounts of $H$. glycines in a single experiment would be necessary to better understand this potential interaction.

ILeVO reduced root weights in most of our greenhouse experiments. However, roots grown from seed treated with fluopyram (nonformulated ILeVO) did not have significantly reduced root weights compared with the nontreated control. The root weight reductions that were detected were in 30-day greenhouse experiments and were possibly associated with the phytotoxic effects of fluopyram, which are reported to not result in long-term stunting or yield loss in one soybean study (Wise et al. 2015). We did not conduct experiments for longer periods of time to determine if the reduced root weights would have persisted.

Exudates collected from seed treated with ILeVO inhibited both H. glycines hatching and motility as much as $98 \%$. Exudates collected from radicles grown from ILeVO-treated seed reduced hatching in only one experimental run and did not affect motility of the J2. These results suggest that fluopyram is possibly most concentrated around the seed, and a small amount may move either on or through the emerging radicle. The variability of the data from the hatching studies using ILeVO radicle exudates do not allow us to make strong conclusions on its effect on $\mathrm{H}$. glycines hatch. But our results suggest that nematodes near the seed would likely be the most affected by the fluopyram seed treatment. However, movement of fluopyram from the seed would presumably be downward through the soil, possibly explaining why we observed reduced $H$. glycines root penetration in soybean grown from ILeVO-treated seed.

Fluopyram belongs to the family of systemic fungicides known as the succinate-dehydrogenase inhibitors and is used to control fungal diseases in a number of crops (Ishii et al. 2011; Vitale et al. 2016). Formulated as ILeVO, it is one of the few labeled seed treatments with activity on the causal pathogen of soybean sudden death syndrome (SDS), Fusarium virguliforme (Kandel et al. 2016). Interestingly, research in the last few years has documented nematicidal or nematistatic properties of fluopyram (Broeksma et al. 2014; Faske and Hurd 2015). Zaworski (2014) found that ILeVO reduced $H$. glycines reproduction under greenhouse conditions in some experiments but not in others. Additionally, Faske and Hurd (2015) reported that fluopyram inhibited motility of M. incognita and Rotylenchulus reniformis but that the inhibition was largely reversible after rinsing the nematodes with water, suggesting a nematistatic effect. Faske and Hurd (2015) also reported that brief exposure of both nematode species to fluopyram resulted in reduced root infection of tomato. Jones et al. (2017) reported reduced $M$. incognita damage to lima bean when fluopyram was applied to the soil before planting. Our results suggest that the effects of ILeVO on $H$. glycines are similar to effects of the product on $M$. incognita and $R$. reniformis. It also is possible

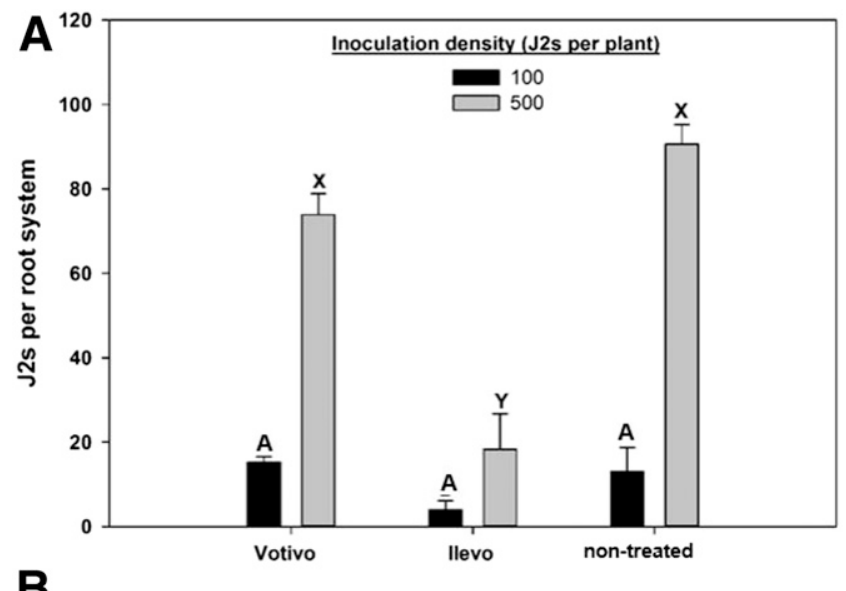

B

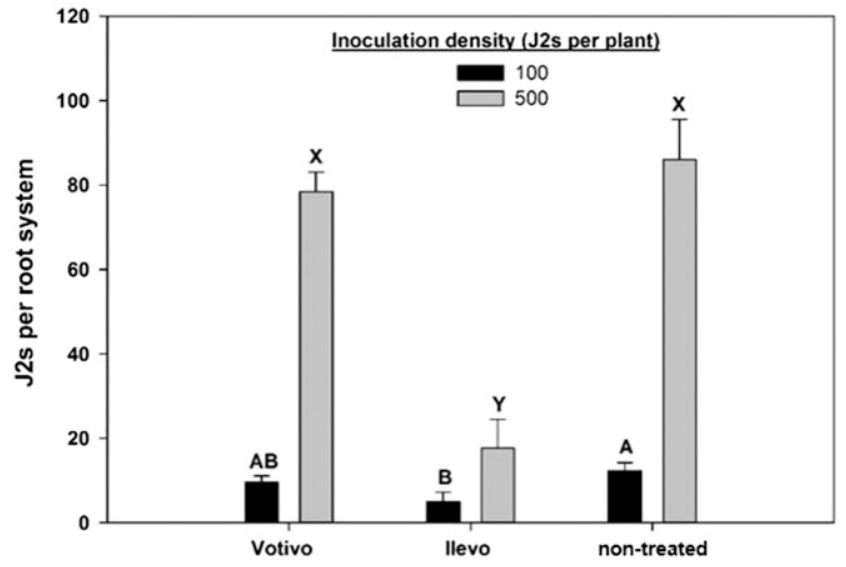

Fig. 3. Effect of seed treatments on root penetration of Heterodera glycines juveniles (mean \pm standard error of the mean) at A, 1 and $\mathbf{B}, 3$ days after inoculation. There were 10 replications for each treatment over two runs. Bars of the same color with different letters are significantly different from one another according to Tukey's honest-significant-difference test $(\alpha=0.05)$. 
that fluopyram induces plant defenses, resulting in nematode protection, but this hypothesis has not been studied thus far.

To date, there have been few published field studies examining the effect of ILeVO on $H$. glycines or other plant-parasitic nematodes. ILeVO suppressed SDS symptoms and increased soybean yields in multistate field studies but the effect of the seed treatment on $\mathrm{H}$. glycines was not studied (Kandel et al. 2016). A recent field trial evaluating the effect of ILeVO on M. incognita found no effect of the seed treatment on nematode population densities or soybean yield (Hurd et al. 2015). However, additional studies across diverse environments are needed to better determine the effect of ILeVO on H. glycines.

Our experiments demonstrate that ILeVO has activity on $H$. glycines under controlled conditions. However, the limited time and spatial conditions of our experiments may have produced significant effects that may not be relevant under field conditions. For example, the cone-tainers used in the greenhouse and root-penetration experiments could restrict the fluopyram in the root zone in a way that would provide for greater root protection than would occur in the field. It is possible for a compound to show strong activity against a plant-parasitic nematode under controlled conditions, yet provide little or inconsistent protection in the field. For example, abamectin was reported to be nematicidal for $M$. incognita and $R$. reniformis at concentrations as low as $1 \mu \mathrm{g} / \mathrm{ml}$ in laboratory experiments (Faske and Starr 2006) but the same compound did not reduce plant-parasitic nematode symptoms on cotton roots (Faske and Starr 2007) or increase yields when used as a seed treatment (Faske 2006).

We observed no consistent effects of VOTiVO on $H$. glycines in any of the experiments conducted. B. firmus I-1582 (the AI of VOTiVO) reportedly colonizes growing root tissue and provides a barrier between nematodes and roots. Schrimsher (2013) reported a reduction in $H$. glycines $\mathrm{J} 2$ hatching and motility when exposed to cells of $B$. firmus I-1582 in vitro. Additional split-root experiments suggested that the bacterium induces systemic resistance in the plant. The bacterium reduced $R$. reniformis reproduction on cotton, but only at higher rates of $B$. firmus (Castillo et al. 2013). In contrast, a number of field trials have reported no effect of VOTiVO on yields or on population densities of a number of different species of plantparasitic nematodes (Jackson and Behn 2010; Land et al. 2014; Musil et al. 2014). The inconsistency in the nematode-protectant properties of VOTiVO may be due to several factors, including competition from other soil microbes, less-than-optimal environmental conditions (such as soil $\mathrm{pH}$ or moisture), or experimental design. Our experiments used only seed-applied VOTiVO and were limited to early soybean growth. Longer experiments may be necessary for the bacterium to grow and begin affecting the nematodes. For example, Crow (2014) found that B. firmus I-1582 significantly reduced Belonolaimus longicaudatus population densities only after 2 months after application of the bacteria, indicating that there may be a lag time before B. firmus I-1582 is effective in controlling plant-parasitic nematodes. Sterility did not alter the effect of VOTiVO seed and radicle exudates in the hatching and motility experiments, indicating that the lack of activity was not due to the presence or absence of $B$. firmus I-1582 cells. Additional experiments for longer periods of time or in altered environmental conditions could provide a clearer picture of how and when VOTiVO provides nematode protection.

There are a few important considerations to be made regarding our methods and results in the hatching and motility experiments. First, ILeVO radicle exudates reduced hatching modestly in one experimental run and not in another. In addition, radicle exudates stimulated hatching compared with the water in only one run, and the overall rate of hatching in the second run was much higher than the first. The variability associated with the radicle exudate hatching experiment may be potentially explained by the effects of environmental conditions on the soybeans grown to produce $H$. glycines eggs. Hominick et al. (1985) found considerable variation in the response of the potato cyst nematode Globodera rostochiensis to potato root exudates and attributed these effects to environmental conditions such as photoperiod during development of the nematodes on the plants. Stimulation of $H$. glycines hatch in response to soybean exudates also has been reported to be variable across experimental runs (Charlson et al. 2008). Because we repeated experiments over time, the $H$. glycines eggs used in our studies were from soybean plants grown under greenhouse conditions at different times of the year. It is possible that our inconsistent results are due to environmental variability in the greenhouse we used to culture $H$. glycines. Although the effects of ILeVO seed exudates on $H$. glycines was highly consistent across runs, our data do not allow for firm conclusions to be drawn regarding the effects of radicle exudates.

Second, our motility studies relied on using a wire probe to assess motility of individual $\mathbf{J} 2$. However, assessing response of nematodes to drops of $\mathrm{NaOH}$ or $\mathrm{Na}_{2} \mathrm{CO}_{3}$ has been reported to be a more accurate method of assessing immobility of nematode (Chen and Dickson 2000; Xiang and Lawrence 2016). It is possible that the immobilized nematodes we observed in the ILeVO seed exudate would still respond to $\mathrm{NaOH}$ or $\mathrm{Na}_{2} \mathrm{CO}_{3}$. Thus, it is important to note that the immobilization of $\mathbf{J} 2$ in ILeVO seed exudates in our study may not necessarily indicate nematode mortality.

Although seed treatments likely cannot provide season-long protection against plant-parasitic nematodes, decreases in nematode infection and reproduction in early seedling development have been associated with increased yields and reduced plant damage. For example, Huang and Ploeg (2001) found that delaying Longidorus africanus infestation by 10 days resulted in increased biomass in both lettuce and carrot. Additionally, Shane and Barker (1986) found that older soybean plants are less sensitive to $M$. incognita infection than young ones. These studies suggest that nematode population densities may be suppressed and plant damage reduced if seed treatments can temporarily reduce or eliminate $H$. glycines infection in young soybean plants. However, the effects and interactions among nematode population densities, environment, and other pathogens may hinder efforts to provide a consistent benefit of seed treatments to soybean growers. Additional studies examining the effects of VOTiVO, ILeVO, and other seed treatments in the field and on the biology of $H$. glycines are necessary for the full potential of this management tool to be understood and appreciated.

\section{Acknowledgments}

We thank Bayer CropScience for providing treated seed and funding the research, the Graduate Minority Assistantship Program at Iowa State University for providing funds for this project, and Z. Dietz for assistance in data collection.

\section{Literature Cited}

Allen, T. W., Bradley, C. A., Sisson, A. J., Byamukama, E., Chilvers, M. I., Corker, C. M., Collins, A. A., Damicone, J. P., Dorrance, A. E., Dufault, N. S., Esker, P. E., Faske, T. R., Fiesler, L. J., Grybauskas, A. P., Hershman, D. E., Hollier, C. A., Isakeit, T., Jardine, D. J., Kelley, H. M., Kemerait, R. C., Kleczewski, N. M., Koenning, S. R., Kurle, J. E., Malvick, D. K., Markell, S. G., Mehl, H. L., Mueller, D. S., Mueller, J. D., Mulrooney, R. P., Nelson, B. D., Newman, M. A., Osborne, L., Overstreet, C., Padgett, G. B., Phipps, P. M., Price, P. P., Sikora, E. J., Smith, D. L., Spurlock, T. N., Tande, C. A., Tenuta, A. U., Wise, K. A., and Wrather, J. A. 2017. Soybean yield loss estimates due to diseases in the United States and Ontario, Canada, from 2010 to 2014. Plant Health Prog. 18:19-27.

Barham, J. D., Kirkpatrick, T. L., and Bateman, R. 2005. Field evaluations of Avicta, a new seed-treatment nematicide. Ark. Agric. Exp. Stn. Res. Ser. 543:128-134.

Broeksma, A., Puetzkuhl, K., Lamprecht, S., and Fuersch, H. 2014. Velum ${ }^{\circledR}$-An evolutionary nematicide for efficient crop production. J. Nematol. 46:140-141.

Byrd, D. W., Kirkpatrick, T., and Barker, K. R. 1983. An improved technique for clearing and staining plant tissues for the detection of nematodes. J. Nematol. 15:142-143.

Castillo, J. D., Lawrence, K. S., and Kloepper, J. W. 2013. Biocontrol of the reniform nematode by Bacillus firmus I-1582 GB-126 and Paecilomyces lilacinus 251 on cotton. Plant Dis. 97:967-976.

Charlson, D. V., Harkings, K. R., and Tylka, G. L. 2008. Relationship between juvenile hatching and acridine orange fluorescence of Heterodera glycines eggs. Nematology 10:603-610.

Chen, S. Y., and Dickson, D. W. 2000. A technique for determining live secondstage juveniles of Heterodera glycines. J. Nematol. 32:117-121.

Crow, W. T. 2014. Effects of a commercial formulation of Bacillus firmus I-1582 on golf course bermudagrass infested with Belonolaimus longicaudatus. J. Nematol. 46:331-335.

Epps, J. M., and Young, L. D. 1981. Evaluation of nematicide and resistant cultivar for control of soybean cyst nematode race 4. Plant Dis. 65:665-666. 
Faghihi, J., and Ferris, J. M. 2000. An efficient new device to release eggs from Heterodera glycines. J. Nematol. 32:411-413.

Faske, T. R. 2006. Efficacy of abamectin as a seed treatment for control of Meloidogyne incognita and Rotylenchulus reniformis. Ph.D. dissertation, Texas A\&M University, College Station, TX.

Faske, T. R., and Hurd, K. 2015. Sensitivity of Meloidogyne incognita and Rotylenchulus reniformis to fluopyram. J. Nematol. 47:316-321.

Faske, T. R., and Starr, J. L. 2006. Sensitivity of Meloidogyne incognita and Rotylenchulus reniformis to abamectin. J. Nematol. 38:240-244.

Faske, T. R., and Starr, J. L. 2007. Cotton root protection from plant-parasitic nematodes by abamectin treated seed. J. Nematol. 39:27-30.

Gaspar, A. P., Marburger, D. A., Mourtzinis, S., and Conley, S. P. 2014. Soybean seed yield response to multiple seed treatment components across diverse environments. Agron. J. 106:1955-1962.

Gray, F. A., and Soh, D. H. 1989. A nematicide seed treatment to control Ditylenchus dipsaci on seedling alfalfa. J. Nematol. 21:184-188.

Hominick, W. M., Forrest, J. M. S., and Evans, A. A. F. 1985. Diapause in Globodera rostochiensis and variability in hatching trials. Nematologica 31: $159-170$.

Howard, D. D., Chambers, A. Y., and Lessman, G. M. 1998. Rotation and fertilization effects on corn and soybean yields and soybean cyst nematode populations in a no-tillage system. Agron. J. 90:518-522.

Huang, X., and Ploeg, A. T. 2001. Effect of plant age and Longidorus africanus on the growth of lettuce and carrot. J. Nematol. 33:137-141.

Hurd, K., Faske, T. R., and Emerson, M. 2015. Evaluation of Poncho/VOTiVO and ILeVO for control of root-knot nematode on soybean in Arkansas, 2014. Plant Dis. Manage. Rep. 9:N017.

Ishii, H., Miyamoto, T., Ushio, S., and Kakishima, M. 2011. Lack of crossresistance to a novel succinate dehydrogenase inhibitor, fluopyram, in highly boscalid-resistant isolates of Corynespora cassiicola and Podosphaera xanthii. Pest Manage. Sci. 67:474-482.

Jackson, T. A., and Behn, J. L. 2010. Evaluation of VOTiVO biological seed treatment nematicide on lesion nematodes of corn in Nebraska, 2009. Plant Dis. Manage. Rep. 4:N033.

Jenkins, W. R. 1964. A rapid centrifugal-flotation technique for separating nematodes from soil. Plant Dis. Rep. 48:692.

Jones, J. G., Kleczeski, N. M., Desaeger, J., and Meyer, S. L. F. 2017. Evaluation of nematicides for southern root-knot nematode management in lima bean. Crop Prot. 96:151-157.

Kandel, Y. R., Wise, K. A., Bradley, C. A., Chilvers, M. I., Tenuta, A. U., and Mueller, D. S. 2016. Fungicide and cultivar effects on sudden death syndrome and yield of soybeans. Plant Dis. 100:1339-1350.

Land, C., Lawrence, K. S., Burmester, C. H., and Norris, C. 2014. Experimental biologicals management of the reniform nematode in North Alabama, 2013. Plant Dis. Manage. Rep. 8:ST014.

McCarville, M. C., Marett, C. C., Mullaney, M. P., Gebhart, G. D., and Tylka, G. L. 2017. Increase in soybean cyst nematode virulence and reproduction on resistant soybean varieties in Iowa from 2001 to 2015 and its effects on soybean yields. Plant Health Prog. 18:146-155.

Mitchum, M. G., Wrather, J. A., Heinz, R. D., Shannon, J. G., and Danekas, G. 2007. Variability in distribution and virulence phenotypes of Heterodera glycines in Missouri during 2005. Plant Dis. 91:1473-1476.

Munkvold, G. P., Watrin, C., Scheller, M., Zeun, R., and Olaya, G. 2014. Benefits of chemical seed treatments on crop yield and quality. Pages 89-103 in: Global Perspectives on the Health of Seeds and Plant Propagation Material. Plant Pathology in the 21st Century (Contributions to the 9th International Congress), Vol. 6. M. Gullino and G. Munkvold, eds. Springer, Dordrecht, The Netherlands.

Musil, K. M., Arenson, N. J., and Giesler, L. J. 2014. Evaluation of biological soybean seed treatments on yield and soybean cyst nematode populations, 2014. Plant Dis. Manage. Rep. 9:N016.

Niblack, T. L., Arelli, P. R., Noel, G. R., Opperman, C. H., Orf, J. H., Schmitt, D. P., Shannon, J. G., and Tylka, G. L. 2002. A revised classification scheme for genetically diverse populations of Heterodera glycines. J. Nematol. 34:279-288.

Niblack, T. L., Colgrove, A. L., Colgrove, K., and Bond, J. P. 2008. Shift in virulence of soybean cyst nematode is associated with use of resistance from
PI 88788. Online publication. Plant Health Prog. doi:10.1094/PHP-20080118-01-RS

Niblack, T. L., Heinz, R. D., Smith, G. S., and Donald, P. A. 1993. Distribution, density, and diversity of Heterodera glycines in Missouri. J. Nematol. 25: 880-886

O'Bannon, J. H., and Reynolds, H. W. 1960. Preliminary studies with DBCP cotton seed treatment for controlling the root-knot nematode. Plant Dis. Rep. 44:484-486.

Oostendorp, M., and Sikora, R. A. 1989. Seed treatment with antagonistic rhizobacteria for the suppression of Heterodera schactii early root infection of the sugar beet. Rev. Nematol. 12:77-83.

Riga, E., Hooper, C., and Potter, J. 2005. In vitro effect of marigold seed exudates on plant parasitic nematodes. Phytoprotection 86:31-35.

Ristaino, J. B., and Thomas, W. 1997. Agriculture, methyl bromide, and the ozone hole. Plant Dis. 81:964-977.

Rodriguez-Kabana, R., Hoveland, C. S., and Haaland, R. L. 1977. Evaluation of a seed-treatment method with acetone for delivering systemic nematicides with wheat and rye. J. Nematol. 9:323-326.

Sasser, J. N., and Uzzell, G. 1991. Control of the soybean cyst nematode by crop rotation in combination with a nematicide. J. Nematol. 23:344-347.

Schrimsher, D. W. 2013. The studies of host plant resistance to the reniform nematode in upland cotton and the effect of Bacillus firmus I-1582 GB-126 on plant-parasitic nematodes. M.S. thesis, Auburn University, Auburn, AL.

Schroeder, N. E., and MacGuidwin, A. E. 2010. Behavioural quiescence reduces the penetration and toxicity of exogenous compounds in second-stage juveniles of Heterodera glycines. Nematology 12:277-287.

Shane, W. W., and Barker, K. R. 1986. Effects of temperature, plant age, soil texture, and Meloidogyne incognita on early growth of soybean. J. Nematol. 18:320-326.

Tefft, P. M., and Bone, L. W. 1984. Zinc-mediated hatching of eggs of soybean cyst nematode, Heterodera glycines. J. Chem. Ecol. 10:361-372.

Tylka, G. L. 2012. Soybean Cyst Nematode Field Guide. Online publication. Ext Outreach Publ. 223. http://lib.dr.iastate.edu/extension_pubs/223

Tylka, G. L., Gebhart, G. D., Marett, C. C., and Mullaney, M. P. 2016. Evaluation of soybean varieties resistant to soybean cyst nematode in Iowa in 2016. Iowa State Univ. Ext. Publ. IPM-52.

Tylka, G. L., Marett, C. C., Robertson, A. E., and Serrano-Porras, M. 2015. Field experiments show effect of Clariva seed treatment in 2014. Integrated Crop Management News: Paper 308. Iowa State University, Ames. http://lib.dr. iastate.edu/cropnews/308

United States Environmental Protection Agency. 1993. 40 CFR Part 82, Protection of Stratospheric Ozone: Final Rule. Fed. Regist. 58:65018-65062.

Vitale, A., Panebianco, A., and Polizzi, G. 2016. Baseline sensitivity and efficacy of fluopyram against Botrytis cinrea from table grape in Italy. Ann. Appl. Biol. 169:36-45.

Wheeler, T. A., Lawrence, K. S., Porter, D. O., Keeling, W., and Mullinix, B. G. 2013. The relationship between environmental variables and response of cotton to nematicides. J. Nematol. 45:8-16.

Wise, K., Mueller, D., Kandel, Y., Young, B., Johnson, B., and Legleiter, T. 2015 Soybean seedling damage: Is there an interaction between the ILeVO seed treatment and pre-emergence herbicides? Integrated Crop Management News, Paper 319. Iowa State University, Ames. http://lib.dr.iastate.edu/cropnews/319

Wong, A. T. S., Tylka, G. L., and Hartzler, R. G. 1993. Effects of eight herbicides on in vitro hatching of Heterodera glycines. J. Nematol. 25:578-584.

Xiang, N., and Lawrence, K. S. 2016. Optimization of in vitro techniques for distinguishing between live and dead second stage juveniles of Heterodera glycines and Meloidogyne incognita. PLoS One 11:e0154818.

Zaworski, E. R. 2014. Effects of ILeVO ${ }^{\circledR}$ on soybean sudden death syndrome and soybean cyst nematode. Graduate Theses and Dissertations. Paper 14261. Iowa State University, Ames. http://lib.dr.iastate.edu/etd/14261

Zhao, X., Schmitt, M., and Hawes, M. C. 2000. Species-dependent effects of border cell and root tip exudates on nematode behavior. Phytopathology 90: $1239-1245$

Zuckerman, B. M., Dicklow, M. B., and Acosta, N. 1993. A strain of Bacillus thuringensis for the control of plant-parasitic nematodes. Biocontrol Sci. Technol. 3:41-46 